\title{
ON THE DETERMINATION OF ARTERIAL OXYGEN SATURATIONS FROM SAMPLES OF "CAPILLARY" BLOOD ${ }^{1}$
}

\author{
By J. L. LILIENTHAL, JR. 2 AND R. L. RILEY 2 \\ (From the Naval School of Aviation Medicine, U. S. Naval Air Training Center, \\ Pensacola, Florida)
}

(Received for publication April 17, 1944)

The attack upon many problems in respiratory. physiology requires the determination of the oxygen saturation of the arterial blood. These determinations in the past have been limited by the difficulties attending repeated arterial puncture in man. It has long been believed that the oxygen content of cutaneous finger blood approximates that of arterial blood. Indirect evidence in support of this belief was first furnished when it was demonstrated that the oxygen saturation of blood obtained from a vein on the dorsum of the heated hand equaled that of blood from the brachial artery (1).

Later it was shown (2) that the oxygen saturation of blood obtained from an incision of the finger tip was equivalent to that of arterial blood. This relationship offered the possibility of estimating the arterial oxygen saturation by analysis of cutaneous blood, but the difficulty in obtaining samples of adequate volume prevented the development of this method. A step toward the solution of this problem has been furnished by the recent development of a microgasometric method for the analysis of blood gases (3). This method makes possible accurate determinations on small samples of blood $(0.04 \mathrm{ml} .)^{8}{ }^{3}$ However, the collection of finger samples large enough for duplicate determinations of both oxygen content and capacity may require massage which results in dilution of

1 The opinions or assertions contained herein are the private ones of the writers and are not to be construed as official or reflecting the views of the Navy Department or the naval service at large.

2 Lieutenant (MC) USNR

8 The accuracy of the microgasometric method has been checked in this laboratory by comparison of analyses performed on the same samples of blood by the Roughton-Scholander method and by the Van SlykeNeill manometric method. The correlation has been found to be within 0.3 volumes per cent. For duplicate analyses by the Roughton-Scholander method, only checks within 0.3 volumes per cent are acceptable. the sample with tissue fluid. This difficulty has been obviated by the use of the ear lobe as a source of "capillary" blood.

This communication reports (1) a simple method for determining the oxygen saturation of samples of cutaneous blood from the heated ear; and (2) the experimental demonstration that the oxygen saturation of cutaneous blood obtained from the heated ear corresponds, within the limits of analytical accuracy, to the oxygen saturation of blood obtained simultaneously from the brachial artery.

\section{METHODS}

The collection of blood samples from the ear lobe necessitates a brief contact of blood with the ambient air. Despite the virtually instantaneous uptake of oxygen by solutions of hemoglobin, it was discovered that a drop of blood may be allowed brief contact with air without effecting a measurable change in oxygen content. This may be due to the negligible number of erythrocytes which are exposed to the gas phase. In order to estimate the effect of such contact with air, the following experiment was performed. The oxygen content of a sample of oxalated venous blood was determined both by the Roughton-Scholander and the Van Slyke-Neill methods. Another portion of the same sample was dropped slowly through air into the collecting funnel and syringe, employed in the method described below, and the oxygen content was determined by the microgasometric method. The results of these analyses follow:

\section{Oxygen content in volumes per cent}

Anaerobic sample Mean

Van Slyke-Neill. ..............5.9, $6.2 \ldots \ldots \ldots .6 .0$

Roughton-Scholander.........5.96, 5.96.......5.96 After transfer dropwise through air

Roughton-Scholander.........5.8, $5.8 \ldots \ldots \ldots .8 .8$

It is apparent that no significant change in oxygen content had occurred as a result of the transfer of blood dropwise through air.

The ear lobe provides an excellent source of "capillary" blood because a deep puncture is virtually painless. Furthermore, full vasodilatation to provide rapid blood flow can be effected easily by the local application of 
heat. The ear is warmed best by radiant heat. The oro-nasal rubber mask furnished for basal metabolism determinations may be converted readily for use as a heater. The inner surface is covered with aluminum paint or any suitable reflecting material and the inlet is modified to hold a small electric light bulb as a source of heat. The mask is then fitted over the ear. Within a few minutes this heater produces full local vasodilatation despite low ambient temperatures.

The ear lobe is punctured with a sharp pointed knife. The puncture should be deeper than the stab used for routine hematological samples and should produce a steady dropping of blood without any massage. The blood is collected directly from the ear into a $2 \mathrm{ml}$. Luer syringe by means of a small glass funnel (Figure 1). Before use, the syringe is rinsed with a 15 per cent

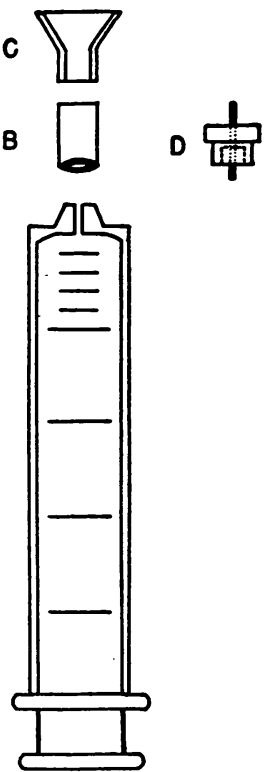

Fig. 1. A. 2 ml. Luer Syringe with Shortened Tip to Reduce Dead Space. B. Rubber Connecting Tube. C. Small Glass Collecting Funnel. D. Rubber Stopper with Wire Plug.

solution of potassium oxalate; the plunger of the syringe is advanced fully and the remaining solution prevents coagulation and obliterates the dead space. As the drops of blood fall into the funnel, they are drawn rapidly into the syringe without admixture of any air bubbles. A sample of 0.4 to $0.5 \mathrm{ml}$. will furnish ample blood to perform the microgasometric analyses in triplicate for both oxygen content and capacity. The funnel and connecting tube are then removed from the syringe and replaced by a rubber stopper with a small hole which is occluded by a removable fine wire. As soon as the syringe is thus sealed it is rotated until all analyses are completed. The Roughton-Scholander sampling pipette may be introduced through the hole in the rubber stopper and aliquots of blood withdrawn under anaerobic con- ditions. After completion of the analyses for oxygen content, the stopper is opened and $1.5 \mathrm{ml}$. of air is drawn into the syringe; rotation is resumed. This air is expelled and replaced every 5 minutes for 3 changes. At the end of 20 minutes, the blood has become completely oxygenated and the microgasometric analyses for oxygen capacity may be performed.

\section{RESULTS}

Oxygen saturations in peripheral and arterial blood have been compared at various levels of oxygen saturation and of ambient temperature by means of appropriate oxygen-nitrogen mixtures administered at sea level and by exposure to simulated pressure-altitudes in the chilled low pressure chamber. In these studies, the samples of arterial blood were drawn at the same time that the cutaneous samples were obtained from the heated ear. This was accomplished by introducing an indwelling needle with blunt stylet into the brachial artery before exposure to low oxygen pressure was begun. The results of these experiments are presented in the accompanying table.

TABLE I

Simultaneous "capillary" and arterial oxygen saturations **

\begin{tabular}{|c|c|c|c|c|c|c|}
\hline \multirow[t]{2}{*}{ Sub- } & \multirow{2}{*}{ Altitude } & \multirow{2}{*}{$\begin{array}{c}\begin{array}{c}\text { Breath- } \\
\text { ing }\end{array} \\
\text { per cent } \\
\mathrm{O}_{2}\end{array}$} & \multirow{2}{*}{$\frac{\begin{array}{c}\text { Tem- } \\
\text { perature }\end{array}}{{ }^{\circ} \mathrm{C} .}$} & \multicolumn{3}{|c|}{ Percentage saturation } \\
\hline & & & & Ear lobe & Artery & Differ- \\
\hline $\begin{array}{l}\text { Fu } \\
\text { Ri } \\
\text { Fu } \\
\mathbf{L i} \\
\mathbf{R i} \\
\mathbf{L i} \\
\mathbf{R i} \\
\mathbf{L i} \\
\mathbf{D u} \\
\mathbf{P o} \\
\mathbf{L i} \\
\mathbf{R o} \\
\mathbf{R i} \\
\mathbf{L i} \\
\mathbf{R o}\end{array}$ & $\begin{array}{c}\text { Sea level } \\
\text { Sea level } \\
\text { Sea level } \\
\text { Sea level } \\
14,000 \\
14,000 \\
14,000 \\
25,000 \\
\text { Sea level } \\
\text { Sea level } \\
\text { Sea level } \\
\text { Sea level } \\
\text { Sea level } \\
\text { Sea level } \\
25,000\end{array}$ & $\begin{array}{r}12.0 \\
13.0 \\
13.0 \\
13.0 \\
20.94 \\
20.94 \\
20.94 \\
\text { “100.0" } \\
20.94 \\
20.94 \\
20.94 \\
20.94 \\
20.94 \\
\text { “100.0" } \\
\text { "100.0" }\end{array}$ & $\begin{array}{r}24 \\
24 \\
24 \\
24 \\
22 \\
22 \\
-20 \\
-20 \\
24 \\
24 \\
24 \\
24 \\
24 \\
24 \\
22\end{array}$ & $\begin{array}{l}84.3 \\
82.0 \\
86.9 \\
84.0 \\
75.7 \\
80.5 \\
77.5 \\
96.8 \\
97.7 \\
96.7 \\
94.3 \\
96.8 \\
95.6 \\
102.2 \\
102.0\end{array}$ & $\begin{array}{l}87.0 \\
84.0 \\
87.3 \\
86.2 \\
76.2 \\
80.6 \\
74.4 \\
96.4 \\
98.3 \\
96.9 \\
94.8\end{array}$ & $\begin{array}{l}-2.7 \\
-2.0 \\
-0.4 \\
-2.2 \\
-0.5 \\
-0.1 \\
+3.1 \\
+0.4 \\
-0.4 \\
-0.2 \\
-0.5 \\
.\end{array}$ \\
\hline
\end{tabular}

** These data represent a series of consecutive experiments made after the preliminary trials during the evolution of the method.

*** Not recalculated for dissolved oxygen due to higher partial pressures.

The experiments presented indicate that there is no significant difference between the oxygen saturations of arterial blood and of cutaneous blood obtained from the heated ear. The variations in the samples obtained at the same time are no greater than might occur in duplicate determinations in which the range of accuracy of the analysis is 0.3 volumes per cent. 
The volume of the wet anti-coagulant employed in this method is sufficiently large with respect to the size of the blood sample to preclude estimation of the absolute oxygen contents and capacities. However, the dilution factor for content and capacity is the same in any one sample so that the determination of saturation is accurate. Absolute contents might be determined, if required, by weighing the dry syringe, weighing again after the addition of the anti-coagulant, and finally after the introduction of the blood sample, in order to calculate the actual dilution. The use of a dry anti-coagulant and a mineral oil seal has not proved feasible with these small samples of blood.

\section{BIBLIOGRAPHY}

1. Meakins, J., and Davies, H. W., Observations on the gases in human arterial and venous blood. J. Path. and Bact., 1920, 23, 451.

2. Lundsgaard, $C$., and Moeller, E., Investigations on the oxygen content of cutaneous blood (so-called capillary blood). J. Exper. Med., 1922, 36, 559.

3. Roughton, F. J. W., and Scholander, P. F., Micro gasometric estimation of the blood gases. I. Oxygen. J. Biol. Chem., 1943, 148, 541. 